\title{
IMPROVING THE CORROSION RESISTANCE OF MILD STEEL BY ZINC-GRAPHENE OXIDE COATINGS
}

\author{
NICOLETA COTOLANa , GRAZIELLA LIANA TURDEAN ${ }^{a}$, \\ JULIETA DANIELA CHELARUa,"
}

\begin{abstract}
The main purpose of this work is to improve the corrosion resistance of steel substrates using the characterization of new composite zinc electrodeposits containing graphene oxides and reduced graphene oxide. The zinc-graphene based composite deposits were obtained by electrodeposition of an acidic electrolyte $(\mathrm{pH}=5)$ at a current density of $20 \mathrm{~mA} / \mathrm{cm}^{2}$. Anionic surfactant (i.e., sodium dodecyl sulfate) was used to obtain uniform and compact coating morphology. Also, the investigated deposits had in their structure the graphene oxides produced by graphite exfoliation and the results concerning corrosion behavior of the zinc electrodeposits (Zn/S235 and Zngraphene/S235) were compared using the same experimental conditions. Microstructural characterization was carried out by SEM-EDS, whereas corrosion resistance was evaluated by EIS and polarization curves.
\end{abstract}

Keywords: Graphene Oxide, Electrochemical Impedance Spectroscopy, Polarization Curves, Corrosion Resistance, Steel Corrosion

\section{INTRODUCTION}

Steel is one of the most widely used materials in the industry and it is a subject of corrosion in industrial environments. The corrosion of steel has a great impact on economics thus, it is imperative to protect it. Coatings are one of the most cost-effective and practical strategies to protect a steel surface against attack from an aggressive species. Zinc is widely used as a sacrificial coating by providing a barrier in the traditional steel anticorrosion field and has an important role in protecting steel substrates. However, its lifespan is limited in aggressive environments, especially in humid conditions [1]. There

\footnotetext{
a Babeş-Bolyai University, Faculty of Chemistry and Chemical Engineering, 11, Arany Janos St., RO-400028, Cluj-Napoca, Romania,

*Corresponding author: jdchelaru@chem.ubbcluj.ro
} 
are several ways to improve the corrosion resistance of zinc-coated steel, varying from chromating the zinc surface to its coating with organic molecules and the incorporation of useful nanoparticles in the zinc coating [2].

Recently, research works have revealed that electrochemical methods are also powerful tools to prepare graphene materials through electrochemical exfoliation of graphite both in ionic liquids or aqueous solutions for ultracapacitors [3]. From several past years' graphene has been at forefront of research because of its spectacular physics properties [4] and application potential arising from its unusual mechanical, thermal, optical, chemical, and electrical properties. Application of graphene for corrosion protection has been explored by various research groups due to its impermeability to ions and molecules [5].

Graphene oxide (GO) is one of the most commonly used materials for graphene-based applications. In the last decade, several synthesis routes have been proposed to prepare GO, such as: mechanical exfoliation [6], chemical vapor deposition [7], and thermal decomposition [8]. The most attractive property of GO is that it can be (partially) reduced to graphene-like sheets by removing the oxygen containing groups with the recovery of a conjugated structure [9].

Graphene (G), graphene oxide (GO) and reduced graphene oxide (rGO), has shown its potential use in anti-corrosion coating for metal substrates. Kirkland et al. [10] employed graphene as a corrosion protection barrier for nickel and copper. Singh et al. [11] reported the fabrication of a robust graphene-reinforced composite coating with excellent corrosion resistance by aqueous cathodic electrophoretic deposition. Ramezanzadeh et al. [12] developed a sol-gel based silane film filled with functionalized GO nanosheets to enhance the epoxy coating resistance against corrosion and cathodic delamination over the steel substrate [13].

In this context, the aim of the study was the preparation of zincgraphene-based composite deposits and their characterization. The anticorrosion protective ability of the composite deposits in case of mild steel tested in an acidic solution was investigated by electrochemical methods (polarization measurements and electrochemical impedance spectroscopy).

\section{RESULTS AND DISCUSSION}

\section{Microstructural characterization}

The influence of graphene oxide on the composition and structure of zinc-graphene deposits were investigated by Scanning Electron Microscopy in conjunction with Energy Dispersive Spectroscopy (SEM-EDS) methods. Figure 1 shows the SEM images of Steel substrate (S235), Zn/S235, 
Zn-rGO/S235 and Zn-GO/S235 deposits and Figure 2 shows EDS images for Zn-rGO/S235 and Zn-GO/S235 deposits. The images show a visual idea in which the formation of a protective film on the steel surface occurs to reduce the corrosion rate. It can be observed in the presented morpho-structural results that the surface morphology is different in all cases and a possible explanation could be the rearrangement of the zinc deposit microstructure in the presence of graphene materials.
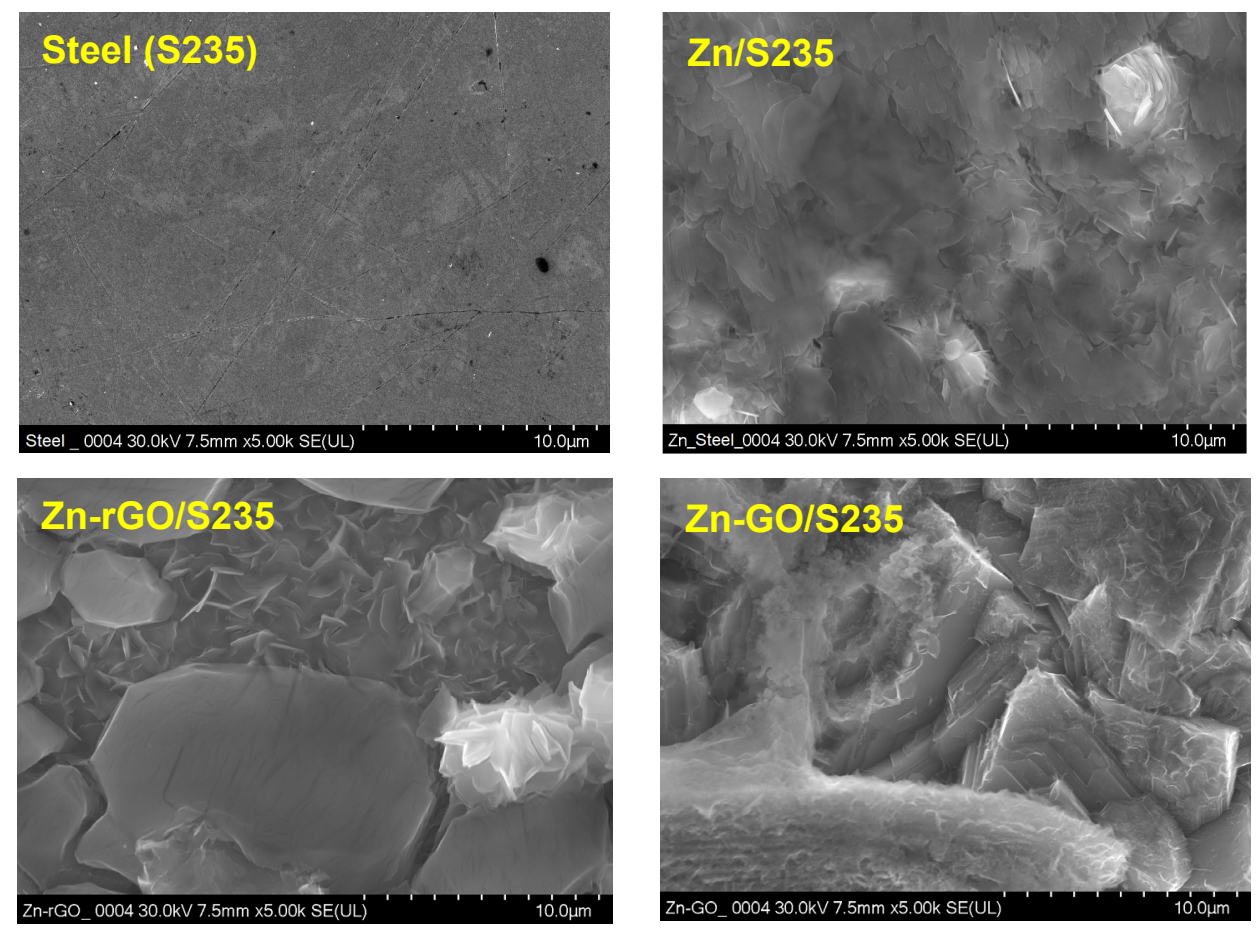

Figure 1. SEM micrographs of S235, Zn/S235, Zn-rGO/S235 and Zn-GO/S235.

Also, from the SEM micrographs can be observed a successful codeposition of GO in Zn matrix. The coatings: Zn-rGO/S235 and Zn-GO/S235 present inclusive and uniform deposits than Steel and Zn/S235 samples. 

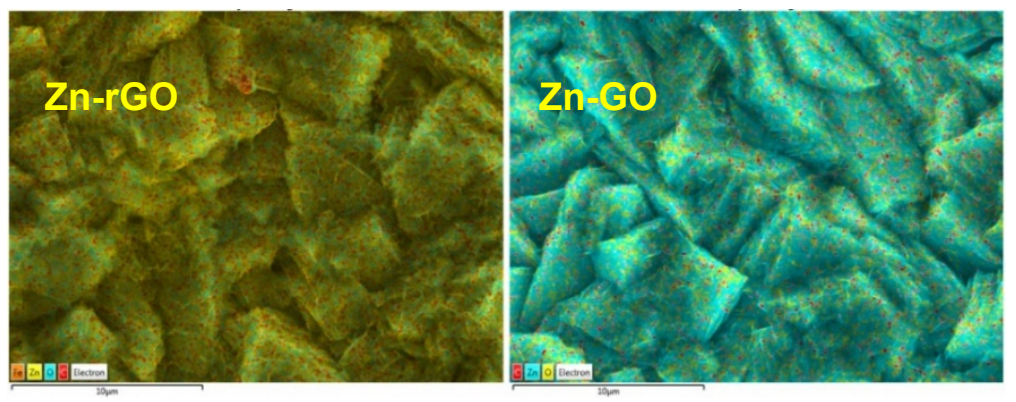

Figure 2. EDS quantitative $X$-ray microanalysis for $Z n-r G O / S 235$ and Zn-GO/S235 deposits.

The elemental composition was determined by EDS investigation on the surface coating of the steel samples deposits. Analyzing the images from Figure 2 it can be observed a uniform distribution of the elements which makes up the deposit on the surface of the steel samples. As it can be seen from Table 1, the EDS analysis indicated in both cases that $\mathrm{Zn}$ has a large proportion but were also present $\mathrm{O}, \mathrm{C}$ and $\mathrm{Fe}$. The presence of the $\mathrm{Fe}$ in the substrate can be easily attributed to steel samples, while the presence of the $O$ and $C$ may be due to the process of coatings preparation. Since rGO was synthesized via the reduction of $\mathrm{GO}$, the presence of oxygen was still noticeable, possibly due to the remaining oxygen functional groups in the air-dried $Z n-r G O$. It can be noticed a high percentage of $\mathrm{Fe}$ and $\mathrm{O}$ in the $\mathrm{Zn}$-rGO deposit compare with the $\mathrm{Zn}-\mathrm{GO}$ substrate. The occurrence of these elements may involve the formation of Fe oxides in the substrates. Based on the identification of the elements in the composite coatings ( $Z n-r G O$ and $Z n-G O)$ deposited on the steel surface, rather it is expected a good corrosion protection if use $\mathrm{Zn}-\mathrm{GO}$.

Table 1. The weight percentage of the detected elements by the EDS on the samples surface region of the $\mathrm{Zn}-\mathrm{rGO}$ and $\mathrm{Zn}-\mathrm{GO}$ composite coatings (wt \%)

\begin{tabular}{|l|r|r|r|r|}
\hline \multicolumn{1}{|c|}{ Sample } & Zn & \multicolumn{1}{c|}{$\mathbf{0}$} & \multicolumn{1}{c|}{ C } & \multicolumn{1}{c|}{ Fe } \\
\hline Zn-rGO & 57.29 & 22.78 & 2.50 & 17.43 \\
\hline Zn-GO & 79.82 & 7.68 & 12.35 & 0.15 \\
\hline
\end{tabular}

\section{Corrosion tests of the coatings}

\section{Open circuit potential}

The corrosion resistance of coatings was characterized by electro-chemical impedance spectroscopy and Tafel plots. In order to determine the corrosion behavior of mild steel (S235), in acidic media $3 \mathrm{wt} . \% \mathrm{NaCl}$, in the presence of $\mathrm{Zn}$ 
and $\mathrm{Zn} /$ graphene based coatings, the experiments were started by recording the open circuit potential (OCP). The OCP was measured vs. Ag/AgCl/KCl and become relatively constant after $1 \mathrm{~h}$. The OCP values were situated around $-500 \mathrm{mV}$ for steel samples and around $-1 \mathrm{~V}$ for zinc deposited ones.

\section{Electrochemical impedance spectroscopy}

The EIS plots were recorded, immediatly after open circuit potential (OCP), in order to investigate the corrosion protection efficiency of $\mathrm{Zn}, \mathrm{Zn}$ rGO, Zn-GO and Zn-2GO coatings. The results are presented in Figures 3 and 4. From the Nyquist plots, it can be observed that the impedance spectra are characterized by two time constants (or two capacitives loops). The impedance spectra were analyzed for all cases by fitting the experimental data with a $R_{e}\left(Q_{\text {coat }}\left(R_{\text {coat }}\left(Q_{d l}(R c t)\right)\right)\right)$ equivalent electrical circuit (Figure 5$)$. The equivalent electrical circuit from Figure 5 consists of:

- the $R_{c t}-Q_{d l}$ elements, exhibiting a loop at high frequencies, represents the charge transfer resistance $R_{c t}$ and the constant phase element corresponding to the double layer capacity, $Q_{d l}$, at the coated steel | electrolyte interface.

- the $R_{\text {coat }}-Q_{\text {coat }}$ elements, exhibiting a loop at low frequencies, where $R_{\text {coat }}$ represents the resistance of the corrosion products accumulated the interface and $Q_{\text {coat, }}$, the constant phase element corresponding to the capacity due to an oxidation-reduction process occurring into the coating layer

- $R_{e}$ represents the electrolyte resistance between the reference electrode and the work electrodes surface,

- coefficients $n_{d l}$ and $n_{\text {coat }}$ represent the depressed feature of the capacitive loop in Nyquist diagram $(0<\mathrm{n} \leq 1)$.

In order to understand the electrochemical process occurring at the work electrodes surface, the parameters for all samples were obtained by using the proposed equivalent electrical circuit. The quality of fitting procedure was evaluated by the chi squared $\left(x^{2}\right)$ values, which were of order $10^{-4}$. The results are shown in Table 2.

Table 2. The electrochemical impedance parameters estimated by fitting the experimental impedance data from Figure 2.

\begin{tabular}{|c|c|c|c|c|c|c|c|c|}
\hline \multirow[b]{2}{*}{ Sample } & \multirow[b]{2}{*}{$\begin{array}{c}R_{e} \\
\mathrm{k} \Omega \cdot \mathrm{cm}^{2}\end{array}$} & \multirow{2}{*}{$\begin{array}{c}\mathrm{R}_{\text {coat }^{\mathrm{a}}} \\
\mathrm{k} \Omega \cdot \mathrm{cm}^{2}\end{array}$} & \multicolumn{2}{|l|}{$Q_{\text {coat }}$} & \multirow{2}{*}{$\begin{array}{c}\mathrm{R}_{\mathrm{ct}}^{\mathrm{a}} \\
\mathrm{k} \Omega \cdot \mathrm{cm}^{2}\end{array}$} & \multicolumn{2}{|l|}{$Q_{d l}$} & \multirow{2}{*}{$\begin{array}{c}R_{p} \\
k \Omega \cdot \mathrm{cm}^{2}\end{array}$} \\
\hline & & & $\begin{array}{c}\mathrm{Y}_{0, \text { coat }^{\mathrm{b}}} \\
\mu \Omega^{-1} \cdot \mathrm{cm}^{-2} \mathrm{~s}^{\mathrm{n}}\end{array}$ & $n_{\text {coat }}{ }^{\mathrm{C}}$ & & $\begin{array}{c}\mathrm{Y}_{0,\left.\mathrm{~d}\right|^{\mathrm{b}}} \\
\mathrm{m} \Omega^{-1} \cdot \mathrm{cm}^{-2} \mathrm{~s}^{\mathrm{n}}\end{array}$ & $n_{d l^{c}}$ & \\
\hline $\mathrm{Zn}$ & 0.012 & 0.072 & 128.20 & 0.62 & 0.174 & 9.16 & 0.81 & 0.250 \\
\hline$\overline{Z n-r}$ & & & 9.41 & 0.69 & & 9.14 & 0.64 & 0.398 \\
\hline Zn-GO & & 194 & 40.12 & 0.80 & 0.284 & 12.54 & 0.76 & 0.478 \\
\hline Zn-2GO & 0.012 & 0.296 & 95.75 & 0.54 & 0.335 & 9.80 & 0.81 & 0.631 \\
\hline
\end{tabular}

aThe standard error for $R_{\text {coat }}, R_{c t}$ values was between $1.05 \%-5.18 \%$;

${ }^{b}$ The standard error for $Q_{\text {coat }}, Q_{d l}$ values was between $3.10 \%-4.31 \%$;

cThe standard error for $n$ values was between $0.81 \%-3.51 \%$. 


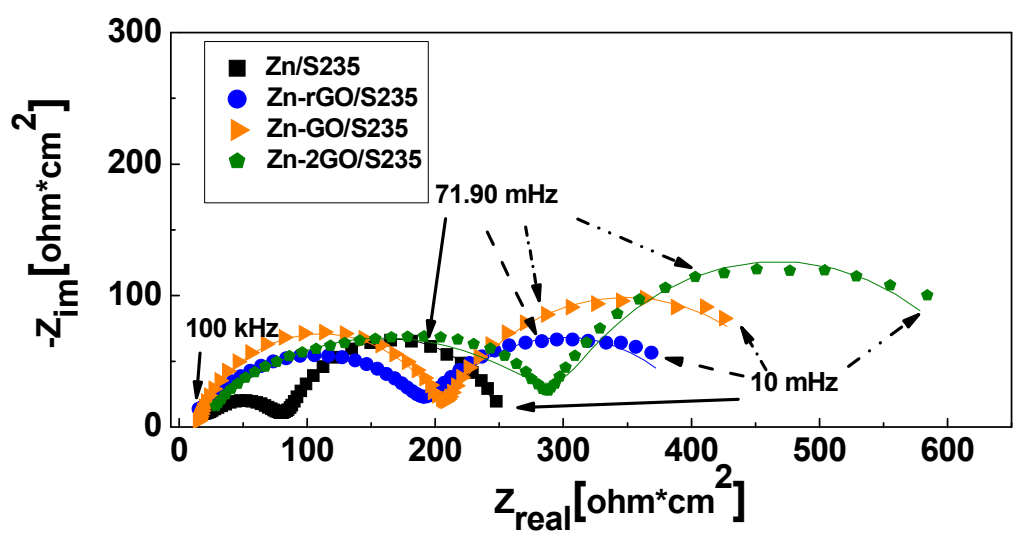

Figure 3. Nyquist impedance diagrams for the $\mathrm{S} 235$ electrodes coated with Zn, Zn-rGO, Zn-GO and Zn-2GO, immersed in $3 \mathrm{wt} . \% \mathrm{NaCl}$; the lines represent fitted data.

Based on the data from Table 2, it can be observed that the highest polarization resistance (obtained by the sum: $R_{p}=R_{c t}+R_{c o a t}[14]$ ), which is an indicator of corrosion resistance, was obtained in the case of $\mathrm{S} 235$ coated with the $\mathrm{Zn}-2 \mathrm{GO}$. Thus, increasing the quantity of GO in $\mathrm{Zn}$ coating favors the corrosion resistance of the S235. It can be presumed that the degree of inhibition depends on the amount of incorporated graphene, which also depends on the GO type.

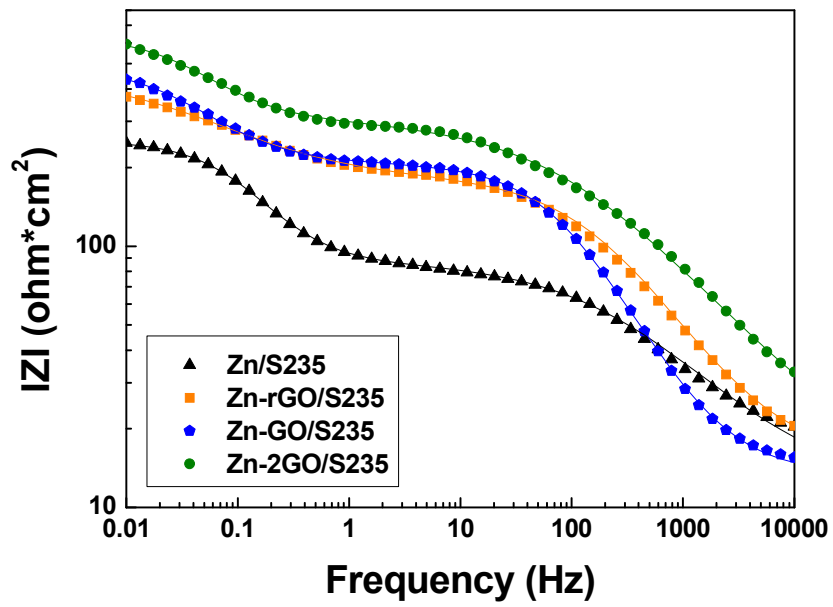

Figure 4. Bode plots for the steel electrodes coated with Zn, Zn-rGO, Zn-GO or $\mathrm{Zn}-2 \mathrm{GO}$ immersed in $3 \mathrm{wt} . \% \mathrm{NaCl}$; the lines represent fitted data. 


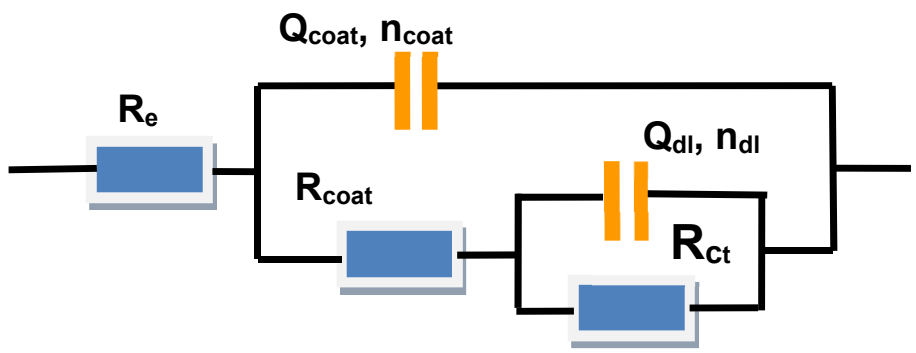

Figure 5. The equivalent electrical circuit used for fitting of the experimental results.

An increase of the absolute impedance at low frequencies region $\left(10^{2} \mathrm{mHz}\right.$ ) in Bode plots (Figure 4) can be observed, in case of using oxide graphene coatings, suggested an improvement of the corrosion resistance.

\section{Polarization measurements}

In order to determine the corrosion current density ( $\left.\mathrm{i}_{\text {corr }}\right)$ and the corrosion potential $\left(\mathrm{E}_{\text {corr }}\right)$ were recorded the potentiodynamic polarization curves in the potential range of $\pm 200 \mathrm{mV} v s$. OCP (Figure 6). For all the coatings, the results obtained by Tafel interpretation of the polarization curves are presented in Table 3. Based on these results it can be seen that the value of $\mathrm{i}_{\text {corr }}$ decreased in all cases when used graphene oxide coatings, compared with $\mathrm{Zn}$ coated sample. This behavior can be due to the inclusion of the graphene oxide materials in the metallic deposit.

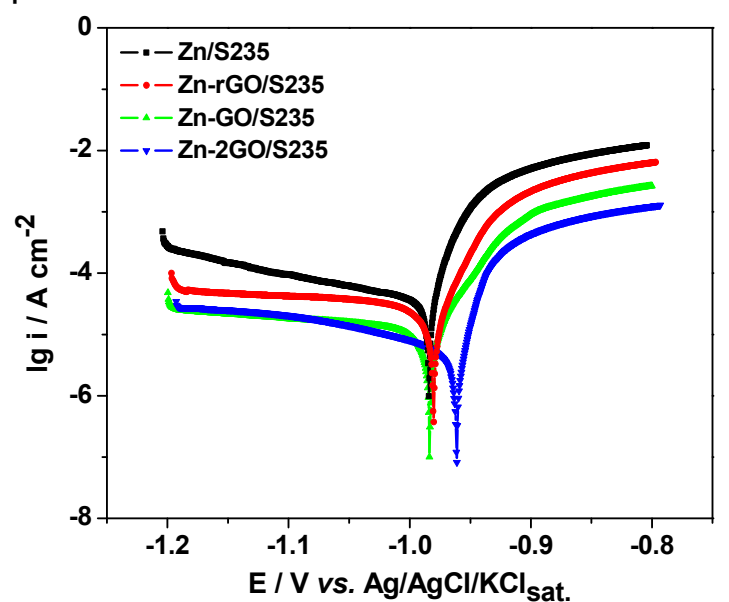

Figure 6. Tafel polarization curves recorded for steel coated with different type of $\mathrm{Zn}$ and $\mathrm{Zn}-\mathrm{GO}-$ based protective deposits (see inset). Experimental conditions: current density, $20 \mathrm{~mA} / \mathrm{cm}^{2}$; deposition time, 20 minutes. 
Table 3. The corrosion parameters, estimated by extrapolation of the Tafel curves of each sample

\begin{tabular}{|l|c|c|c|c|}
\hline \multicolumn{1}{|c|}{ Sample } & Zn & Zn-rGO & Zn-GO & Zn-2GO \\
\hline Concentration of rGO/GO (mg/L) & - & 50 & 50 & 100 \\
\hline$E_{\text {corr }}(\mathrm{mV}$ vs. Ag/AgCl/KClsat) & -996 & -983 & -986 & -963 \\
\hline$I_{\text {corr }}(\mu \mathrm{A})$ & 64.71 & 26.91 & 11.74 & 6.35 \\
\hline Corrosion Rate $(\mathrm{mm} /$ year $)$ & 0.0751 & 0.03122 & 0.01362 & 0.00736 \\
\hline
\end{tabular}

An important parameter for measuring the corrosion resistance is the corrosion rate. Based on Faraday's law, the corrosion rate (CR) can be calculated by the following equation [15]:

$$
\mathrm{CR}=\frac{\mathrm{K} \cdot \mathrm{I}_{\mathrm{corr}} \cdot \mathrm{EW}}{\rho \cdot \mathrm{A}}
$$

Where $\mathrm{K}=3272(\mathrm{~mm} / \mathrm{A} \cdot \mathrm{cm} \cdot$ year $)$ is the corrosion rate constant

I corr is corrosion current $(A)$

$\mathrm{EW}=27.9225 \mathrm{~g}$ is equivalent weight of $\mathrm{Fe}$

$\rho=7.874 \mathrm{~g} / \mathrm{cm}^{3}$ is the density of Fe

$\mathrm{A}=0.5 \mathrm{~cm}^{2}$ is sample surface area.

The corrosion rate values are summarized in table 3 . It can observe that the GO exhibited better corrosion protection property than Zn and Zn-rGO. In the case of using coating containing $G O$ the protective effect increases after doubling its concentration. Thus, for $2 \mathrm{GO}$, the value of $\mathrm{CR}$ decreases almost half compared with the value of $C R$ in the case of GO. This behavior is in agreement with the results obtained from the EIS measurements.

\section{CONCLUSIONS}

In this paper, the corrosion resistance of two types of Zn/graphene based coatings on steel was examined. According to the electrochemical investigations, both coatings ( $\mathrm{Zn}-\mathrm{rGO}$ and $\mathrm{Zn}-\mathrm{GO}$ ) led to increasing the corrosion resistance of $\mathrm{S} 235$ steel compare with $\mathrm{Zn}$ coating. But a significant increase of the polarization resistance and decrease in the corrosion rate was observed for $\mathrm{Zn}-\mathrm{GO}$ composite coating. Thus, the amount of GO material was raised and the obtained results have shown that the concentration gradient of GO material in zinc sulphate electrolyte has an important effect on the corrosion resistance. The corrosion rate for the $\mathrm{Zn}-\mathrm{GO}$ composite coating has decreased by an order of magnitude, by doubling the amount of $\mathrm{GO}$ in coatings. 


\section{EXPERIMENTAL SECTION}

\section{Materials and solutions}

The electrochemical cell contained three electrodes: working electrode (WE), reference electrode (RE), and counter electrode (CE). A steel (S235) disk electrode was the $\mathrm{WE}, \mathrm{S}=0.5 \mathrm{~cm}^{2}$. The $\mathrm{Ag} / \mathrm{AgCl} / \mathrm{KCl}$ sat was used as $\mathrm{RE}$ and a $\mathrm{Pt}$ foil as $\mathrm{CE}$. The $\mathrm{S} 235$ steel sample had the following composition: $0.22 \% \mathrm{C}, 0.85 \% \mathrm{Mn}, 0.055 \% \mathrm{P}, 0.055 \% \mathrm{~S}$ and Fe balance. The surface of the S235 electrodes was examined by optical microscopy the results were reported previously [16]. WEs were cut from a steel bar and introduced in a Teflon cylinder; a copper rod was attached for ensuring electrical contact. Before using, the working electrode was wet polished on emery paper of different granulation (up to 2000 grade) and finally on felt with a suspension of alumina. After that, the electrode was ultrasonicated for 2 minutes, degreased with ethanol, and washed with distilled water in order to remove all the impurities from the surface and then dried at room temperature.

The acidic solution for corrosion measurements was the electrolyte with the following composition: $320 \mathrm{~g} / \mathrm{L} \mathrm{ZnSO} 4,10 \mathrm{~g} / \mathrm{L} \mathrm{NaCl}, 30 \mathrm{~g} / \mathrm{L} \mathrm{Na}_{2} \mathrm{SO}_{4}$ and 0.05 $\mathrm{g} / \mathrm{L} \mathrm{CH}{ }_{3}\left(\mathrm{CH}_{2}\right)_{11} \mathrm{SO}_{4} \mathrm{Na}$ or sodium dodecyl sulfate (SDS) with $\mathrm{pH}=5$. All the reagents were obtained from Merck, Germany. All the coatings including pure $\mathrm{Zn}$ were electrodeposited using the same SDS concentration in order that corrosion behavior of the coatings can be studied as a function of GO content alone.

Two types of graphene materials were used for the zinc composites electrodeposition process: (i) water-ethanol graphene oxide $\mathrm{GO}$ suspension obtained by the method of protected sono-oxidative exfoliation of graphite (GO); (ii) commercial reduced graphene oxide (rGO), purchased from Graphenea, Spain. The preparation and characterization of GO material were described in detail by A. Pérez del Pino et al. [17].

\section{Morpho-structural investigations}

The Scanning Electron Microscopy (SEM) was performed using an Ultra High Resolution (UHR) SEM Hitachi 8230 system operated in high vacuum conditions. The instrument capabilities allow particular scanning options in order to show the distribution of components in relation to their chemical composition and topography of the studied surface. High resolution SEM images acquired at low landing voltage can be assessed without the destruction of the samples. The SEM accelerating voltage was $15 \mathrm{kV}$ in a vacuum of $10^{-5} \mathrm{mbar}$ and secondary electrons images combined with Energy Dispersion Spectroscopy (EDS) analysis were used to investigate the morphological properties.

\section{Electrochemical methods}

The electrodeposition samples were obtained on a PC - controlled electrochemical analyzer PAR 2273 (Princeton Applied Research, USA). 
The corrosion measurements were performed with a computer-controlled potentiostat AUTOLAB, PGSTAT302 N (Eco Chemie BV, Utrecht, Netherlands) and GPES/FRA program was used for data analysis. The open circuit potential for steel immersed in the corrosive solution was monitored for 1 hour. Electrochemical impedance spectroscopy (EIS) measurements were carried out at OCP, in the frequency range of $100 \mathrm{kHz}-10 \mathrm{mHz}$ at 10 points per decade with an $A C$ voltage amplitude of $\pm 10 \mathrm{mV}$. Electrochemical impedance data were fitted using ZSimpWin 3.21 software. Immediately after the EIS measurement were recorded the polarization curves by scanning in a potential range of \pm 200 $\mathrm{mV}$ vs. open circuit potential (for Tafel interpretation) with a scan rate of 0.166 $\mathrm{mV} / \mathrm{s}$. The testing temperature was $21^{\circ} \mathrm{C} \pm 2{ }^{\circ} \mathrm{C}$.

\section{ACKNOWLEDGMENTS}

The authors would like to thank dr. Cosmin Cotet for the supply of graphene oxide material and dr. Lucian Barbu-Tudoran for SEM-EDS analysis.

\section{REFERENCES}

1. R. Jain; R. Pitchumani; Surf. Coat. Tech., 2018, 337, 223-231.

2. C.T.J. Low; R.G.A. Wills; F.C. Walsh; Surf. Coat. Tech. 2006, 201, 371-383.

3. A. Ambrosi; M. Pumera; Chem-Eur. J., 2016, 22, 153-159.

4. S. K. Choudhary; A. K. Gupta; Solid State Commun., 2011, 151, 396-399.

5. M. Schriver; W. Regan; W.J. Gannett; A.M. Zaniewski; M.F. Crommie; A. Zettl; ACS Nano, 2013, 7, 5763-5768.

6. M. Yi; Z. Shen; J. Mater Chem. A., 2015, 3, 11700-11715.

7. G. Allaedinia; E. Mahmoudia; P. Aminayib; S. Masrinda Tasirina; A. Wahab Mohammad; Synth. Met., 2016, 220, 72-77.

8. X. Chen; D. Meng; B. Wang; B.W. Li; W. Li; C.W. Bielawski; R.S. Ruoff; Carbon, 2016, 101, 71-76.

9. A.B. López-Oyama; M.A. Domínguez-Crespo; A.M. Torres-Huerta; E. OnofreBustamante; R. Gámez-Corrales; N. Cayetano-Castro; Diam. Relat. Mater., 2018, 88, 167-188.

10. N.T. Kirkland; T. Schiller; N. Medhekar; N. Birbilis; Corros. Sci., 2012, 56, 1-4.

11. B.P. Singh; S. Nayak; K.K. Nanda; B.K. Jena; S. Bhattacharjee; L. Besra; Carbon, 2013, 61, 47-56.

12. B. Ramezanzadeh; A. Ahmadi; M. Mahdavian; Corros. Sci., 2016, 109, 182-205.

13. J. Zhao; X. Xie; C. Zhang; Corros. Sci., 2017, 114, 146-155.

14. X. Shen; J. Sheng; Q. Zhang; Q. Xu; D. Cheng, J. Mater. Eng. Perform., 2018, 27, 3750-3761.

15. S. Ryu; Y.J. Kwon; Y. Kim; J. Uk Lee; Mater. Chem. Phys., 2020, 250, 123039123047.

16. J.D. Chelaru; D. Aylakov, L.M. Mureşan, Studia UBB Chem., 2017, 4,357-368.

17. A. Pérez del Pino; E. György; C. Cotet; L. Baia; C. Logofatu; RSC Advances, 2016, 6, 50034-50042. 